\title{
Organization Theory and Military Metaphor: Time for a Reappraisal?
}

Dr Alistair Mutch

Professor of Information and Learning, Nottingham Trent University

Department of Information Management and Systems, Burton Street, Nottingham, NG1 4BU

Telephone: 01158482429

Fax: $\quad 01158486512$

Email: $\quad$ alistair.mutch@ntu.ac.uk

Alistair Mutch is Professor of Information and Learning at Nottingham Trent University. He is interested in the application of ideas drawn from critical realism to the study of organizations and has just completed work on strategic change in UK brewing from 1950 to 1990 . He is particularly concerned with the development of historical approaches to the growth of management and has published extensively on public house management in historical journals. This focus has now widened to develop an engagement with institutionalist forms of analysis in exploring the history of management practice and thought. 
Acknowledgements

I wish to thank Sir Charles Tidbury for the initial prompt to look again at military metaphors. I am not sure the article has turned out quite the way he (or I!) originally imagined, but I hope the result is of interest. My thanks as well to referees for preventing me from making some silly mistakes and for prompting me to develop the argument. Some of the research for this article was supported by an ESRC award number R000223773. 


\title{
Organization Theory and Military Metaphor: Time for a Reappraisal?
}

\begin{abstract}
A 'conventional' use of military metaphor would use it to convey attributes such as hierarchical organisation, vertical communication and limited autonomy. This is often used in contrast to a looser form of organisation based on the metaphor of the network. However, this article argues that military practice is more complex, with examples of considerable autonomy within the constraints of central direction. It is suggested that not only might this be a more useful metaphor for many contemporary organizations, but also that simplistic uses of military metaphor divert our attention away from the functions that management hierarchies play. The discussion is embedded within a critical realist account of metaphor, arguing for both its value and the need for its further development.
\end{abstract}

\section{Introduction}

The development of theory is language borne; language is profoundly metaphorical in character (Lopez, 2001, 2003b; Lakoff and Johnson, 1980). If we accept these two assertions, then the character of the metaphors that we use in developing theories about how organizations operate needs to be laid open to scrutiny. Metaphors carry with them a weight of association, symbolism and imagery that, if not scrutinised, 
have the potential to lead our inquiries astray or render them rather less productive than we would like. One of the central sources for models, analogies and metaphors in the development of organization theory has been the domain of military practice and theory. Terms like the distinction between 'line' and 'staff', for example, or 'rank and file’ owe their origins to analogies with military practice. In this article, I want to explore the use of military metaphor in the inter-twined areas of strategy and structure. There is, I will argue, a 'conventional' use of such metaphors that draws on a widespread reading of military practice. In that reading, strategy is reserved for and devised by a small group of senior officers and implemented in a disciplined fashion by lower ranks. In this reading, structure follows on from strategy and comprises a command and control structure, represented visually by the classic organisational pyramid. That such a reading forms a part of conventional thinking about management and that it reflects part of military practice is not denied, but research into the formation of organizational strategy suggests alternative readings of at least a significant part of military practice. I hope to show both the extent of the conventional reading and the interesting questions posed by a different reading. In particular, I will suggest that an alternative model of military practice that suggests a degree of autonomy within a strong regimental culture whilst retaining the potential for tight central discipline might form a more useful way of looking at contemporary business organisations than the customary polarization between hierarchies and networks.

The material on the use of metaphor in organizational analysis suggests a number of approaches. There has been considerable interest in exploring the literary devices that might be used, going beyond the use of metaphor to explore, for example the potential 
of paradox and irony to shed new light on organizational practice. (Oswick, Keenoy and Grant, 2002). For the purpose of this article, I am using the term 'military metaphor' to refer to any form of analogical reasoning from military practice to that of organizations, whilst recognising the very important debate about the varieties of metaphor and their place within the deployment and development of rhetoric (Tsoukas, 1993; Alvesson, 1993; Oswick and Grant, 1996; Inns, 2002). From this focus on the nature and value of different literary devices there has also developed an important emphasis on the generation of new types of analogy that will, it is suggested, help with the process of organizational change (Sackman, 1989). However, Mangham (1996) has argued that that there is a limit to this process and that we may obtain more value from closer attention to the more widely used conventional metaphors, an argument that has some influence on the exploration of military metaphor that I engage in here. The main concern of the article is with the use of military metaphors in organizational theory, as opposed to the way in which they are used in organizations themselves. Before bracketing the question of 'metaphor-inuse', however, it is useful to recognise the performative nature of metaphors.

In organizational practice, metaphors drawn from a wide range of domains are used with little regard to their origins. That is, the use of metaphor by organizational actors escapes its conditions of production. Those actors may have no knowledge of the practices from which the metaphor was derived, and this is of no consequence for their use of the metaphor. The important issue, therefore, is not whether their use of metaphor is 'accurate' with regards to the domain of origin, but the performative effects that its use has. Take for example, the following drawn from a large banking group in the United Kingdom: 
I find that probably HOB is like largely conservative, [HOB's parent banking group] has got a command-control type of structure, almost a military type of structure and that type of structure doesn't react well to changes of this nature (Knights et al, 2002: 102).

We, broadly speaking, know what the speaker means in his use of 'almost a military type of structure'. His analogy creates images of uniformed officers giving orders which will be obeyed because of their rank, and we can transfer these images to a world of suits and wood-panelled boardrooms. In such cases, what we might be interested is not whether practice in the organization is actually like military practice, but what effects such language use has on action within the organization. We might point out that the view of military life that is being deployed is inaccurate or misleading, or that it has become divorced from changes in military practice, but the usage has gained a life of its own. When a former area manager in control of a number of managed public houses, (in observing that it was rare in the 1960s for public house managers to become area managers), comments 'That was not particularly acceptable because the areas were so small [that] you were known and it was felt that you couldn't transfer from to being soldier to an officer', we can suggest that a particular view of organizational life, one that rests on an acceptance of discipline and its maintenance, is being deployed. ${ }^{1}$

And, of course, we could apply the same strictures to the use of metaphor in organizational analysis. Some might argue that the relations between the metaphors we use and the domain of origin might seem of little importance. In the case of those 
who are arguing for the potential of metaphor in organizational transformation, what is of importance is how they enable us to think differently about the world of organizations (Sackmann, 1989; Morgan, 1997). However, we need to consider the performative nature of metaphor in our analyses. That is, a taken-for-granted use of, for example, the 'military=mechanical” analogy might influence the rest of our analysis, possibly, as will be argued below, by setting up a misleading polarisation of organizational models. We might want to pay some attention to the words of warning supplied by Inns and Jones who counsel that 'it may be necessary to unpack a metaphor for its meaning and check understanding before it is used for analysis’ (Inns and Jones, 1996: 123). For simply because our language use is saturated in metaphor does not mean that we cannot judge between the adequacy of different metaphors and judge some more useful than others. This call for precision in our use of metaphor, for an awareness of the commitments that they bear with them, should not be taken to support the position that we might broadly called 'scientific realism', a position that seeks to expunge metaphor from our scientific vocabulary (Inns, 2002). Such a position is untenable and unproductive given what we know about language use. As Lopez persuasively argues from a basis in critical realism, theoretical writing is not a transparent process of rendering thought visible. The language that is used shapes that thought, entangled as it is in a network of references. As he notes

theoretical writing resists our desire for clarity and transparency by denoting and connoting more than we intend. It engenders connections that we have not consciously or actively willed, connections that may very well undermine the theoretical effect we are trying to achieve or perhaps achieve more than we thought was possible (Lopéz, 2003b: 144). 
Such a focus on language may come as a surprise to those who confuse critical, realism with the ‘scientific realism’ espoused by some in organizational analysis (McKelvey, 2003). However, critical realists do not argue that our knowledge of the world is based on direct access to that world. Rather, they contend that our knowledge is socially constructed and so language and metaphor play a central part in that construction. Indeed, in domains such as economics it has been critical realists who have argued trenchantly for the need to use analogical reasoning to develop theory and practice (Lewis, 1999). Their efforts in this regard can be grounded in the work of Lakoff and Johnson (1980), whose account of the origins of metaphor lays particular stress on the role of embodied experience of the world. As they suggest 'the structure of our spatial concepts emerges from our constant spatial experience, that is, our interaction with the physical environment. Concepts that emerge in this way are concepts that we live by in the most fundamental way' (Lakoff and Johnson, 1980: 56). Of course, the subsequent development and application of metaphor in the social world elaborates our stock of metaphors, but this is a useful reminder that language exists in relationship to external referents and is not an enclosed system. Hence, critical realists can comfortably engage with critical discourse analysts in advocating the need to take semiosis ('the intersubjective production of meaning') seriously (Fairclough, Jessop and Sayer, 2002: 2). In this endeavour it is suggested that we need to consider 'extra-discursive conditions of existence and effectivity (Fairclough, Jessop and Sayer, 2002: 9). That is, an understanding of the nature of the language that we use and its entailments does not mean that we are simply trapped in networks of metaphors and their referential networks. Rather, it suggests that we should open our use of metaphors to inspection, to examine the nature of what they denote and 
connote. This article, then, is concerned with our use of military metaphor in organizational theory and not with the use of such metaphors in practice by organizational actors. It is concerned in particular with the ways in which the use of military metaphor might constrain our analysis or perpetuate the use of untenable dualisms.

What the article seeks to argue is that a dominant use of military metaphor in organizational theory is to present a picture of organizations as subject to command and control, with strict hierarchies. Such images are then counter-posed to more fluid analogies, particularly those based on networks. Network organisations, characterised by empowerment and lateral communication, with shifting constellations of project teams, forming and disbanding in line with ever-changing goals, are held to characterise the 'Information Age' (Castells, 2000; Ransome, 1999). But what if military practice is not all about command and control? What if there are alternative models of practice which emphasise relative autonomy? And what if such models suggest more helpful ways of looking at organizations in the contemporary world? What, that is, if our concentration on command and control models has lead us to posit a false bi-polar scale, one which over-emphasises the degree of empowerment and the lack of hierarchy in contemporary organizations? In the rest of this article, I seek to supply some evidence to support the contentions made and to provide some arguments based on the alternative models that this discussion reveals. Briefly, I will outline the evidence for the dominance of the command and control model. I will suggest that there is a 'taken for granted' position that underplays the complexity to be found in the work of, for example, Urwick. I then develop this argument about the complexity of military practice by supplying some brief details of the development of 
light infantry practice and theory. This presents us with an alternative source of analogies which are then applied to contemporary organizational practice, with the aim of providing some answers to the questions just raised.

\section{Military metaphor: the conventional position}

It would be easy to start this discussion by looking at a standard management text, such as Hannagan (1998) and explore the influence of our conventional military model on the discussion of organizational structure and practice. However, this would be to fall into the trap of the simple polarisation that I argue characterizes much of the use of military analogy. A more interesting and complex example, which I select in part because I am familiar with it and in part because I think that it demonstrates the prevalence of an equation of military practice with hierarchy and control is a popular text on systems thinking and information, Mike Harry’s (2001) Business Information : A Systems Approach. I chose this because it explicitly uses military analogy as arguing for what is seen as wrong with mainstream managerialist work. In distinction to the counter-posing of a simple 'systems-control' to a processual-relational perspective that is often found in more critical works on organizations (Watson and Harris, 1999), I would argue that Harry’s book attempts to supply a more nuanced discussion, trying hard to argue that the notion of hierarchy in systems thinking is not isomorphic with organizational hierarchy. His discussion of organizational hierarchy starts with the interesting statement, for our purposes, that 'many early management gurus, like Urwick (1943), saw this business of management very much in military terms' (Harry, 2001: 19). Setting aside for now the accuracy or otherwise of this characterization of Urwick (whose work we return to below), what Harry does is to 
argue that mainstream writers (his main example is Hannagan (1998)) use military practice to construct their pyramidical diagrams of the various levels of management. Such diagrams, characterized by Harry as 'the author's academic enemy no. 1', set up false divisions between managers, with the attribution to some of 'strategic' decisions and to others of 'operational' decisions, based on their position in the hierarchy (Harry, 2001: 17). 'In an information age,' he argues, 'this is easily shown to be nonsense, even if it were ever true' (Harry, 2001: 19). The need is to move away from such sterile metaphors to more appropriate ones, in his case ones based on systems thinking. What Harry is doing is suggesting that military practice is redundant as a source of analogies, leading as it does to false positions that do not help contemporary managers. Military practice here is equated with a rigid command and control structure in which strategic decisions are taken by those at the top, an inappropriate model for organizations competing in more fluid times. A similar emphasis can be found in Claudio Ciborra's discussion of the creation of formal strategies He points to their roots in military thinking, characterised by a focus on neatness, structure and articulation. He explicitly contrasts this way of thinking to 'tactics, ruses, improvisations, of which drifting is the product and outcome, [which] are contingent procedures indexed by the here and now, and meaningless outside a specific timetagged situation.' (Ciborra, 2002: 93). These examples use the military metaphor to conjure up an image of discipline and control, in which initiative is subordinated to a desire for order. In doing so, they draw upon a powerful image that represents a good deal of military practice and history. But not, it could be argued, all of that practice and history. However, a review of the way in which military metaphor has been used would indicate that it is generally used to conjure up the images associated with it by Harry and Ciborra. 
We can find some examples of direct transfer of military examples into the domain of business organisations, and these examples are in the general area of business strategy. Of course, there is the widespread popularity of Sun Tzu's Art of War as applied to business practice (Krause, 1995). In an example drawing on more recent practice , Clemons and Santamaria (2002) argue that business leaders ought examine recent developments in military strategy, with their focus on manoeuvre, and apply these to their own practice. They have limited comments to make on the implication of such applications for the internal life of organisations. (As do Ries and Trout (1986) in their aggressive espousal of military practice). Of course, the classic work of R. N. Anthony (1964) might be taken as the seminal example of the transfer of military models to organisational analysis, with the categorisation of business decisions into strategic, tactical and operational levels. Indeed, the book has an appendix that explicitly compared current military thinking on strategy with that of some business writing. From this comparison Anthony concludes 'business management should be able to profit from what the military has already learned and published.' This is taken further, as he argues that 'Even more important, the way in which the military does strategic planning, especially the functions of the staff, should be carefully explored by some who are interested in possible business applications (Anthony, 1964: 27). However, we should note that Anthony is more cautious when it comes to applying lessons from the military to other levels of the organisation. He specifically points out that to equate his 'management control' or 'tactical' level of decision making with the military sense of 'tactics' 'has a serious defect. A military tactical maneuver has a definite beginning and end, whereas the management control process relates to a recurring cycle of operations' (Anthony, 1964: 56). The value of 
the military metaphor is therefore seen largely in the context of the interaction of the organisation with its environment, with rather less being said about the consequences for internal organisation. In this, the work can be seen to follow the dominant emphasis of the 'planning' school on the way in which structure follows strategy. (For the classic statement of this, see Chandler (1962); for a useful recent discussion, Whittington, 2001). In such an emphasis, the internal arrangements follow from the construction of strategy and so are taken for granted: the connections with the root metaphor are not explored. However, works such as that of Gareth Morgan (1997) on organisational metaphor sit in a tradition that emphasises the role of management choice in the production and reproduction of organisational structure and culture. Such work is much more concerned with the ways that metaphor shapes the learning and practice of organisations; however, what we find here is a relatively underdeveloped exploration of military metaphor.

An example of the tendency to take military metaphors as unproblematic can be found in the discussion by Dunford and Palmer (1996) of metaphors in the discourse on corporate restructuring. Their analysis indicated that, particularly in justifying the need for change, there was an emphasis on 'imagery with strong military/violence overtones, that is not uncommon in the strategy literature'. (Dunford and Palmer, 1996: 99). What is problematic here is the coupling of 'military' with 'violence'. What this fails to do is to discriminate between metaphors that derive from generalised images of violence, those which are based on the more specific terrain of warfare and those which are based on military practice. Instead, these are read as being isomorphic. That this causes problems might be illustrated by the fact that at least one metaphor that they pick up, that of 'slash and burn' is included by them both 
under the heading of 'military/violence' and under 'horticultural'(Dunford and Palmer, 1996: 103). Within their category of responses to the external world they cite the following: 'declare war on competitors', 'combat tenacious global competitors', 'combat rising costs', turn up the heat on competitors''(Dunford and Palmer, 1996: 100). Whilst we can clearly see that one of these draws directly on war, the other three seem to be more generalised examples of violence. None draws directly on military practice, in that the forms of violence that they draw upon could also be waged by other groups. When they turn to the internal condition of organisations, they give a graphic list of 24 examples, many of which are clearly violent in inspiration - words such as 'killing fields', ‘slaughtering’, ‘bloodletting', etc. However, whilst such images might be the result of military action, they are far from being only associated with it. Indeed, of these 24 words and phrases, only 'frontal assault', 'firing line' and ‘thinning the ranks’ are directly related to military practice (Dunford and Palmer, 1996: 102). When we recall the examples given by our organizational actors and by Harry and Ciborra, then the aspects of military practice that might have more relevance for thinking about organizational practice are those to do with the nature of decision making and the relation of this with organizational structure and action. The rather casual and sweeping use of the term 'military' can conceal those aspects which have more purchase on organizational analysis.

A similar set of assumptions can be found in those accounts which tend to equate military practice with a mechanical model of organizing (Thomas, 2003). Whilst Morgan’s classic account of metaphor does recognise in his discussion of military practice that 'in time, further refinements were introduced, including the idea of decentralizing controls to create greater autonomy of parts in different combat 
situations' (Morgan, 1997: 16), the bulk of his discussion is about the relationship of military practice to mechanistic models of organisation. His discussion is largely based on principles of military organisation drawn from the writing of Frederick the Great. Morgan notes that 'Frederick's aim was to shape the army into an efficient mechanism operating through means of standardized parts’ (Morgan, 1997: 16). From this he argues that subsequent views of organisation drew on such arguments to construct mechanistic views of organisation, characterised by rigid definitions of functions and tight control through hierarchies. The transmission mechanism was writers such as Fayol, Mooney and Urwick, as ‘each theorist codified his insights, drawing on a combination of military and engineering principles’ (Morgan, 1997: 18). The extent of the relative contributions of military and engineering principles is a point to which we can return. However, it is Morgan’s insight about the developments following Frederickian practice that suggests a little more complexity to military practice that we need to explore. It is informative to start our examination of this complexity with the figure of Lyndall Urwick.

\section{The complexity of military practice}

Military experience certainly appears important for Urwick, known as he was by the title of Colonel (a title awarded to him as a civilian during the Second World War) during his management consulting activity. A set of biographical notes drawn up about him in 1958 comments that 'Urwick still startles the business leaders he talks to by drawing his examples of leadership morale, organisation and training, not from industry but from his own military experiences in the first world war' (Cited in Roper, 2000: 202). If we examine his Elements of Administration, we indeed find numerous 
examples drawn from military practice. However, in the context of our discussion so far, it is interesting to note that Urwick both points out the departure of military practice from the strict application of a rigidly hierarchical model and uses military practice to point to contrasts within civilian life. Under the first heading, for example, he points out that successful military communication does not adhere to the dictates of a rigid organisation chart:

The "proper channels, the official channels," were there and were used to confirm and to record agreement already reached by far quicker and friendlier means of communication. If an officer had to use them before that point was attained, it was rightly regarded as a confession of failure, an admission that his organisational arrangements were not supported by good personal relations (Urwick, 1947: 47).

Under the second, he is anxious to point out that military discipline has often to be rigid because the 'law of the situation' makes it so. However, by contrast, he argued 'There is in fact no reason whatever why all discipline of this character which is necessary should not be imposed by consent' (Urwick, 1947: 95) What Roper (2000) points out is the different role that military experience played in Urwick's life and work. At times the value of staff work is played up and Urwick's traumatic front line experience is pushed into the background; at other times the front line experience is given more prominence. Once again, this is not a homogeneous military practice that is drawn upon, but a fragmented one, subject to debate and interpretation. He also points out that Urwick was not a career Army officer, but a reservist who came from a family owned manufacturing company. This might suggest that temporally the idea of 
'engineering' is more important for the development of mechanistic forms of thought about organisations than military analogies. Urwick, for example, gives this priority over his military examples, arguing that 'the mechanistic parallel can be very helpful in discussing organisation. Another name for it, of course, is "the engineering approach”' (Urwick, 1947: 35). Yehouda Shenhav's recent account of the growth of management as a profession in the USA suggests the importance of engineering. He argues that that 'engineers used intensified periods of labor unrest to sell the agenda of management systems to reluctant employers and the public at large.' (Shenhav, 1999: 175). In presenting this model of organizations as technical-rational systems to be administered by engineers, they employed mechanistic models of organizations drawn from engineering practice and so helped shaped the nature of those organizations. As Tsoukas (1993: 333) suggests

there must be something else [other than the nature of metaphor itself] which accounts (partially at least) for the predominance of the machine metaphor. In all probability, this can be found in the rules underlying the operation of modern socio-economic systems and institutions.

Whilst, then, military practice might have been used as a metaphor for such mechanistic organizational practices, this might be misleading. This is not only in the treatment of 'conventional' military practice, but in the substitution of one model of military practice for a variety of practice. That is, military practice and organization is not homogeneous. What I have termed as the 'conventional' picture consists of a tightly structured organization in which there are clear lines of decision making. 
Strategic decisions are taken by a small group of senior officers and the 'implementation' of these decisions is a question of the giving of orders. These orders are transmitted through a clearly defined hierarchy and are followed to the letter. Their operation rests on strict discipline which is rigidly enforced at all levels of the hierarchy. The transmission of information is one way, with no ability to question orders and no feedback from lower in the hierarchy. Individual members of this structure are treated as components, trained to complete their task efficiently and unquestioningly. This is, of course, something of a caricature and one, as that we have seen, was modified in practice. However, if there have been elements of truth in this picture, then it does not account for the full range of military forms.

I want here to bring in a passage from an interview conducted with Sir Charles Tidbury, a former chairman of Whitbread, that alerted me to the potential complexity of military practice. During this interview, on the formation of strategies in the brewing industry, he commented as follows:

And I always said one thing we must never do is fight toe to toe with Allied or Bass or nowadays I would say Scottish and Newcastle. Because if we get clipped it will just be like a punch from Joe Louis and we shall be out of the ring. I mean we had to dance around and that came back from this idea, [the] rifleman's technique of the red coats and the green jackets.

Later he commented of another chairman 
He was a great fellow of great experience, he was a guardsman and they are marvellous. You say you're going to attack that, eight of you are going to be killed and we're going to do it like that, they're all marching towards it and they will do it like that and we were taught really to think round the problems.

These comments suggested the variety of military practice; they also suggested that there might be value in exploring these varieties in more detail, especially as they had clearly influenced organisational practice (or were being used to illustrate that organisational practice).

Military practice, then, comprises a variety of organisational forms. We can broadly conceive of a distinction between 'heavy' and 'light' units, a distinction which might be nicely contrasted, for the British army, in the regimental titles of Guards and Green Jackets. The Guards regiments are those which best correspond to the conventional view, regiments in which the emphasis is centrally on tight discipline and hierarchy. In this, their lineage from the Frederickian tradition of tightly drilled bodies of men executing identical manoeuvres under strict discipline is clear. However, Morgan recognises above that this legacy was a contested one. It began to be contested in the revolutionary wars of the late eighteenth and early nineteenth centuries (Bryant, 1972: Gates, 1987; Gates, 1994; Strachan, 1983). In America but especially in France, the great massed ranks of armies schooled in Frederickian techniques were outmanoeuvred and out-fought by light infantry. Wearing uniforms which helped them to blend in with their surrounding (hence the Green Jackets) and armed with the newly developed rifle, these bodies of men fought in loose groups. Their organisational form 
was characterised by a considerable degree of autonomy in the field, with noncommissioned officers enabled to take decisions when contact might be lost in the heat of battle. Officers were expected to undertake the same training as their ranks and to lead by example as opposed to by fear. This was a dramatically different model to that of Frederick and it spread rapidly to most armies (although not without resistance from officers who perceived that such developments threatened their position and authority).

We have to be careful to acknowledge the deep conservatism of military practice. Despite the success of light units in campaigns such as the Peninsular War, there was resistance to learning from this. The light units were for many years looked down upon by more traditional elements in the officer class, which ensured that little was learned from them in, for example, the training of soldiers (Speirs, 1992; Skelley, 1977). However, a recent work on the contemporary British Army points to an influence of the Green Jackets beyond their numbers, particularly in terms of senior ranking officers. 'They prided themselves,' writes Beevor (1991: 340-1), 'on having more imagination and a less restricted outlook than the Guards. With a tradition of semi-independent action dating back to the eighteenth century, their soldiers were always considered brighter than average, and officers were picked as much for their intellect as for their social connections.' What we have, then, is a sharp contrast within military practice itself. On the one hand we have the heavy regiments, typified by the Guards regiments. Such units have taken on many of the lessons learned from the experience of their light counterparts, but they tended to be exemplified by tight discipline and strict hierarchies, with officers drawn from particular social groups and a considerable gulf between them and the ranks. On the other we have the light units, 
characterised by a considerable degree of responsible autonomy being granted to the rank and file, especially in battlefield situations. It is interesting to note in this a strong similarity between this and Ciborra's notions of tactics ('tactics, ruses, improvisations, of which drifting is the product and outcome, [which] are contingent procedures indexed by the here and now, and meaningless outside a specific timetagged situation') in strong distinction to the image of rule-following automatons under the threat of strict discipline. However, we do need to emphasise that these troops were subject to central discipline and worked within a framework marked by hierarchy and orders from above (Gates, 1987: 101). What we would also note is the strong cultivation of the identification with the regiment, through the centrality of the regimental history conveyed through symbols and stories. In this, the light regiments share common elements with their heavy counterparts. The argument is not that the light units represent a completely alternative form of organisation, but rather that they demonstrate the complexity of military practice. In this, they perhaps suggest alternative ways of looking at other organizational forms. We return, therefore, to the implications of this discussion for organizational theory.

\section{Implications for organization theory}

In the work already cited, Ciborra argues that

If we draw the full consequences of imagining an economy filled by ephemeral, knowledge-based organizations, able to move, disassemble, and reconfigure themselves to meet customer demands and technological innovations ... we need to shift gears, and drop the language of planning, 
controlling, and measuring through which organizations, teams, and projects have been managed so far (Ciborra, 2002: 103).

Of course, it is a matter of empirical enquiry if such 'ephemeral' organisations exist and operate in this way, but it might be more useful to deploy the contrast between Green Jackets and Guards in exploring such organisations. That is, whilst in many organisations there is great store placed on terms like 'empowerment', with an emphasis on situated improvisation and learning, such organisations might still be characterised by tight central control with a continuing hierarchy of command. However, such control and hierarchy may remain muted with action being taken rather in the context of a strong central culture, the building of which might be seen as a central task. The analogy with the Green Jackets seems to catch the key attributes of such 'loose-tight' control much better than looser metaphors.

What we may be doing by our deployment of military practice as synonymous with central command and control is setting up a false bi-polar scale. At one end of the spectrum are organisations characterized by strict hierarchies, with tightly defined offices and information flows which are constrained to vertical flows and marked by downward communication. Such organizations are characterized as being functionally adapted to the world of Fordist mass production, but to be inappropriate to the demands of the 'Information Age'. The focus here, by contrast, is on the metaphor of the network. Such organizations are characterized by low role distance, and by lateral communication flows. They are flat in organisational form and accord considerable degrees of autonomy to customer facing and operational staff. What such an opposition does is to under-estimate the degree to which organisations can combine 
empowerment with hierarchy. The example of the light infantry units, with their strong focus on decentralised decision making supported by strong regimental culture might fit many contemporary organisations better than the looser metaphors of the network. Of course, the degree to which organisations correspond to the various models that we propose is a question for empirical investigation, but the conventional use of the military metaphor perhaps conceals features of contemporary organisational practice.

Colin Hales (2001: 53) has recently suggested that the organizations that Ciborra and others point to are, at best 'confined to a few recurring and celebrated cases'. For most organizations, he argues, there has been rather an intensification of control with considerable exaggeration of shifts towards decentralization and autonomous work teams. He suggests, in particular, that

The principle of hierarchy, where there is co-ordination through individual vertical responsibility and accountability, has not been abandoned, but retained in an attenuated and more efficient form. Centrally-imposed rules, designed to give a heavy steer to managerial conduct, have not been torn up but have been rewritten to focus on results rather than processes (Hales, 2001: 54).

I would suggest that the conventional use of the military metaphor acts as a diversion away from a deeper consideration of the nature of contemporary organisations. To return, for example to the work of Harry, we find a rejection of the supposed hierarchical model of the military tradition but with little consideration of the context 
of managerial activity. His argument, therefore is that he uses 'management to mean what the people who do the managing do; and the management or managers as a name for anyone who does the managing' (Harry, 2001: 16). In such a definition, we have a focus on management as an activity and management as a group of people, but where is the focus on why these people are managing? As Watson reminds us, it is useful to see management in three ways: as activity, as a group of people and as a function (Watson, 1994). That is, managers are in place for a reason. Without such a conception then the study of management becomes one of a technical activity, divorced from its context (Parker, 2002).

This focus on managerial activity to the relative exclusion of context has been the subject of recent critique. Hales (2001), for example, argues that we now know a considerable amount about what managers do and that the task is now to understand what the impacts of this activity are. From a similar perspective, Thomas (2003) also concludes that there has been too great a focus on managerial activity and that we need to pay more attention to the notion of function. In considering this we could argue that hierarchy is functional for a number of reasons. One approach would be to argue that hierarchy is a natural function of complex organization (Simon, 1976). In this, hierarchy is a rational response to technical demands. By contrast, there is an alternative explanation that would focus on the divided nature of society and the need to ensure workplace discipline (Carchedi, 1977). However, an argument that hierarchies in organizations are a mirror or a translation of military practice is to draw our attention away from this debate and from an exploration of the function and persistence of hierarchy in organizations. It does so by giving the impression that hierarchy is a simple mirroring of practice elsewhere, the mistaken translation of an 
organizational model that fails to meet the real needs of a different context. Of course, it could be argued, and with some validity, that whatever the source of hierarchy in organizations, that managers search for models of existing practice that can be translated into a different context. That is, hierarchy might fit the needs of an organization operating in one context, and it then looks for models of organizing elsewhere that have already implemented forms of hierarchy. In this, military forms (or engineering models) are adopted because they are available models, regardless of their fit against some criteria of 'efficiency'.

This argument about the source of organizational practice is one that has parallels in the debates within history about the origins of management, debates that have some resonance for contemporary arguments. Inspired in part by the work of the new institutionalists such as Powell and DiMaggio (1991), Roy (1997) argues that the military supplied a template for early organisational structures, both in terms of existing practices and in terms of the educational formation of significant business leaders. Central in this transfer, he argues were the railroads. In arguing this he is contradicting the arguments of Chandler and others, who argued that the organizational practices of the railroads - clearly defined hierarchies, strict adherence to a rule book, uniformed staff - came from the technical demands of railroad operation. Clearly, this debate is one that requires further historical investigation, but for our purposes its interest lies in the argument we have made about the relative weight of economic pressures in the formation of organizational practices against the claims of what Powell and DiMaggio would call 'mimetic isomorphism', that is, the extent to which organizations copy other organizational forms for non-economic reasons. Of course, for current organizations, the borrowing of practice might not be 
from military practice but, say, from sporting models. However, there does seem to be some merit in continuing to explore the development of military practice and the ways in which this might be drawn upon in contemporary organizations (Pagonis, 1992; Davis, 2003). In doing so, we need to be a little more careful in our characterizations of that practice. If we set up a notion of 'hierarchy=military=bad' against one of 'networks=business-=good' then we may not have to address those features of organisational practice that might be more apparent if we operated with a more sophisticated model of military practice. The argument is therefore not just about whether the command and control metaphor is an 'accurate' reflection of military practice or whether it is useful in looking at organisations. Rather it is one that stresses the performative nature of the military metaphor in organisational analysis. If we think that military practice is only hierarchical then this might lead us to set up a false bi-polar scale which draws our attention away from the continuing persistence and importance of hierarchies in organisations of all types. This is not a question of a normative judgement about hierarchies, but about the adequacy of our conceptualisations.

This perhaps demonstrates the value of a perspective on language which sees it as have an extra-linguistic referent (Norris, 1997; Lopez, 2001). Such a perspective allows us to give due weight to the complexity of language whilst still relating this to material practices. The important point is not to privilege one or the other, but to examine their mutual constitution. Language is often seen as the Achilles Heel of the realist position (Inns, 2002; Edwards, Ashmore, and Potter, 1995) However, a convincing realist account of metaphor can be presented via the work of, for example, Lakoff and Johnson (1980), Archer (2000) and Lopez (2001, 2003a, 2003b). Indeed, 
Lopez points out that it is those who are located in a broadly realist tradition that have written most persuasively about the value of metaphor in the natural sciences. (Lopez, 2003b: 11-13) The problem comes when a writer like Inns (2002) conflates this careful work with those who take a naïve 'scientific realist' approach. It is fair, however, to argue that those from the critical realist tradition who have operated in the domain of social science have paid rather less attention to the nature of metaphor (Lopez, 2003a: 79). Because of this, the role and nature of metaphor have been underexamined. This, then, represents an agenda for those who argue that critical realism forms a useful basis for the exploration of organizations, an agenda that is already being pursued elsewhere (Fairclough, Jessop and Sayer, 2002).

However, what of our exploration of military metaphor? As Morgan argues

It is vital to understand how different metaphors have come into prominence, and how they may advance certain social constructions and social interests over others. This agenda defines an enormous piece of work, and, without question, it needs to be done (Morgan, 1997: 235).

It has been the task of this article to explore these processes in the context of the use of military metaphor. I have suggested that an approach based on critical realism offers us the resources to interrogate our use of metaphor more closely, because it stresses the need to explore the relationship between metaphor and its external referents, and because it supplies a persuasive account of how to approach those external referents. Clearly, as recognised within the tradition, further work is required to develop this perspective, given that relatively little attention has been paid to it in 
the past (Fairclough, Jessop and Sayer, 2002). However, this approach perhaps suggests a need to concentrate attention on more commonly used metaphors and to embed their consideration in their wider context. For example, Fidler noted in his study of senior managers that the most common metaphors deployed were military ones, something which he and others relate to the formation of significant portions of the British business elite (Fidler, 1981: 161; McKibbin, 1998). There is room for further exploration of this connection, as there is for consideration of more contemporary use of metaphor. I have argued that our use of the military metaphor in organizational analysis has tended to operate with a particular conception of what it is that constitutes military practice. This conventional model is based on a reading of military practice as involving a command and control model based on the disciplined implementation of centrally devised strategy. What this has meant, I have argued, is the false polarization of this model against a looser network based model. My suggestion is that the investigation of the heterogonous nature of military practice reveals an alternative model in which a degree of relative autonomy is granted within the framework of a well developed sense of organizational identity and the potential for strict discipline. This is not to argue that hierarchy disappears, but that it is modified. This might be felt to fit contemporary organizations better than the looser models based on network analogies. The danger with the latter is that they tend to divert our attention away from the persistence of hierarchy. A more sophisticated appreciation of the complexities of the metaphors that we draw upon may help in our understanding of contemporary organizational forms.

\section{References}


Alvesson, M. (1993) 'The Play of Metaphors'. in Parker, M. and Hassard, J. (eds.)

Postmodernism and Organizations. London: Sage, 114-131.

Anthony, R. N. (1964) Planning and Control Systems; A Framework for Analysis.

Cambridge, MA: Harvard Business School.

Archer, M. (2000) Being Human: The Problem of Agency, Cambridge: Cambridge

University Press.

Beevor, A. (1991) Inside the British Army. London: Corgi.

Bryant, A. (1972) Jackets of Green: A Study of the History, Philosophy and Character of the Rifle Brigade. London: Collins.

Carchedi, G., (1977) On the Economic Identification of Social Classes London:

Routledge

Castells, M. (2000) The Rise of the Network Society, Oxford: Blackwell

Chandler, A. (1962) Strategy and Structure: Chapters in the History of the Industrial Enterprise. Cambridge, MA: MIT Press.

Ciborra, C. (2002) The Labyrinths of Information: Challenging the Wisdom of Systems. Oxford: Oxford University Press.

Clemons, E. and Santamaria, J. (2002) 'Maneuver Warfare: Can Modern Military

Strategy Lead You to Victory?', Harvard Business Review, 80(4), 56-65.

Davis, M. (2003) 'Shock and Awe’, Socialist Review, March, 16-17.

Dunford, R. and Palmer, I. (1996) 'Metaphors in Popular Management Discourse:

The Case of Corporate Restructuring', in Grant, D. and Oswick, C. (Eds) Metaphor and Organizations London: Sage, 95-109.

Edwards D., Ashmore M. and Potter J. (1995) 'Death And Furniture - The Rhetoric, Politics And Theology Of Bottom Line Arguments Against Relativism', History Of The Human Sciences 8 (2): 25-49. 
Fairclough, N., Jessop, B. and Sayer, A. (2002) ‘Critical Realism and Semiosis’, Journal of Critical Realism, 5(1), 2-10.

Fidler, J. (1981) The British Business Elite: Its Attitudes to Class, Status and Power, London: Routledge \& Kegan Paul.

Gates, D. (1987) The British Light Infantry Arm c. 1790-1815: Its Creation, Training and Operational Role, London: Batsford.

Gates, D. (1994) 'The Transformation of the Army 1783-1815', in Chandler D. (Ed.) The Oxford Illustrated History of the British Army. Oxford: Oxford University Press, , 133-159.

Hales, C. (2001) 'Does it Matter what Managers Do?’, Business Strategy Review, 12(2), 50-58.

Hannagan, T. (1998) Management: Concepts and Practices, London: Financial Times Pitman.

Harry, M. (2001) Business Information: a Systems Approach, Harlow: Pearson.

Inns, D. (2002) 'Metaphor in the Literature of Organizational Analysis: A Preliminary Taxonomy and a Glimpse at a Humanities-based Perspective’, Organization, 9(2), 305-330.

Inns, D. E. and Jones, P. J (1996) 'Metaphor in Organization Theory: Following in the Footsteps of the Poet?'. in Grant, D. and Oswick, C. (Eds) Metaphor and Organizations London: Sage, 110-126.

Knights, D., Noble, F., Vurdubakis, T., and Willmott, H. (2002) 'Allegories of Creative Destruction: Technology and Organization in Narratives of the E-economy’, in Woolgar, S. (ed.) Virtual Society? Technology, Cyberbole, Reality Oxford: Oxford University Press, 99-114.

Krause, D. (1995) The Art of War for Executives. London: Nicholas Brealey. 
Lakoff, G. and Johnson, M. (1980) Metaphors We Live By, Chicago: University of Chicago Press.

Lewis, P. (1999) 'Metaphor and Critical Realism' in S. Fleetwood (Ed) Critical

Realism in Economics: Development and Debate, London: Routledge, 83-101.

López, J. (2001) ‘Metaphors of Social Complexity’, in López, J. and Potter, G. (eds.)

After Postmodermism: An Introduction to Critical Realism, London: Athlone Press, 86-96.

López, J. (2003a) ‘Critical Realism: The Difference it Makes, in Theory’, in

Cruickshank, J. (ed.) Critical Realism: The Difference it Makes, London: Routledge, 75-89.

López, J. (2003b) Society and its Metaphors: Language, Social Theory and Social Structure, London: Continuum

McKelvey, B. (2003) 'From Fields to Science: Can Organization Studies make the Transition?’, in R. Westwood and S. Clegg (Eds), Debating Organization: PointCounterpoint in Organization Studies, Blackwell, Oxford, 47-72.

McKibbin, R. (1998) Classes and Cultures: England 1918-1951, Oxford: Oxford University Press.

Mangham, I. M. (1996) 'Some Consequences of Taking Gareth Morgan Seriously'. in

D. Grant and C. Oswick (Eds) Metaphor and Organizations London: Sage, 21-36.

Morgan, G. (1997) Images of Organization. London: Sage.

Norris, C. (1997) Resources of Realism: Prospects for 'Post-analytic' Philosophy, Basingstoke: Macmillan.

Oswick, C. and Grant, D. (1996) Organisation Development: Metaphorical Explorations. London: Pitman. 
Oswick, C., Keenoy, T. and Grant, D. (2002) 'Metaphor and Analogical Reasoning:

Beyond Orthodoxy', Acadamy of Management Review, 27(2), 294-303.

Pagonis, W. (1992) Moving Mountains: Lessons in Leadership and Logistics from the Gulf War. Boston, Mass: Harvard Business School Press.

Parker, M. (2002) Against Management, Cambridge: Polity.

Powell, W. and DiMaggio, P. (1991) The New Institutionalism in Organizational Analysis, Chicago: University of Chicago.

Ransome, P. (1999) Sociology and the Future of Work, Aldershot: Ashgate.

Ries, A. and Trout, J. (1986) Marketing Warfare, New York: McGraw-Hill.

Roper, M. (2000) 'Re-remembering the Soldier Hero: The Psychic and Social

Construction of Memory in Personal Narratives of the Great War', History Workshop, 50, 181-204.

Roy, W. (1997) Socializing Capital The Rise of the Large Industrial Corporation in America, Princeton: Princeton University Press.

Sackmann, S. (1989) 'The Role of Metaphors in Organization Transformation', Human Relations, 42(6), 463-485.

Shenhav, Y. (1999) Manufacturing Rationality: The Engineering Foundations of the Managerial Revolution, Oxford: Oxford University Press.

Skelley, A. R. (1977) The Victorian Army at Home: The Recruitment and Terms and Conditions of the British Regular, 1859-1899, London: Croom Helm.

Simon, H. (1976) The New Science of Management Decision, New Jersey: Prentice Hall.

Spiers, E. M. (1992) The Late Victorian Army, 1868-1902, Manchester: Manchester University Press.

Strachan, H. (1983) European Armies and the Conduct of War. London: Routledge. 
Thomas, A. (2003) Controversies in Management: Issues, Debates, Answers, London: Routledge.

Tsoukas, H. (1993) ‘Analogical Reasoning and Knowledge Generation in

Organization Theory', Organization Studies, 14(3), 323-346.

Urwick, L. (1947) The Elements of Administration. London: Pitman.

Watson, T. (1994). In Search of Management. Culture Chaos and Control in Managerial Work London: Routledge

Watson, T. and Harris, P. (1999) The Emergent Manager, London: Sage.

Whittington, R. (2002) 'Corporate Structure: From Policy to Practice'. in Pettigrew,

A. Thomas H. and Whittington R. (Eds.) Handbook of strategy and management.

London: Sage, 113-138.

\footnotetext{
${ }^{1}$ This example is taken from interview data; the interviewee was a former area manager for the Midlands brewer Mitchells \& Butlers, later part of the Bass group
} 